\title{
Fluoropolymers for 157/193 nm Lithography: Chemistry, New Platform, Formulation Strategy, and Lithographic Evaluation
}

\author{
H. Ito, H. D. Truong, M. Okazaki, D. C. Miller, N. Fender, \\ P. J. Brock, G. M. Wallraff, C. E. Larson, and R. D. Allen \\ IBM Almaden Research Center \\ 650 Harry Road \\ San Jose, CA 95120, U. S. A \\ HIROSHI@almaden.ibm.com.
}

\begin{abstract}
A copolymer of $t$-butyl 2-trifluoromethylacrylate (TBTFMA) and norbornene bearing hexafluoroisopropanol (NBHFA) as an acid group, which is prepared by radical copolymerization, is employed in our $157 \mathrm{~nm}$ resist. The radical copolymerization of 2trifluoromethylacrylic monomers with norbornene derivatives has been shown to follow the penultimate model much better than the commonly employed terminal model. These copolymers (containing $>50$ mol\% TBTFMA) are too lipophilic to provide good imaging. Blending a NBHFA homopolymer with an optical density (OD) of $1.7 / \mu \mathrm{m}$ at $157 \mathrm{~nm}$ into the copolymers $(\mathrm{OD}=2.5-2.7 / \mu \mathrm{m})$ results in increased hydrophilicity and reduced $\mathrm{OD}(2.2$ $2.0 / \mu \mathrm{m}$ ) and provides high resolution images. A copolymer of TBTFMA with vinyl ethers has been identified as a new platform, which can be prepared facilely by common radical polymerization. Certain vinyl ether copolymers are also compatible with the NBHFA homopolymer and thus blending improves their OD and aqueous base development. Because these fluoropolymers are highly transparent at $193 \mathrm{~nm}$ as well, they are evaluated as $157 / 193$ dual wavelength resists.
\end{abstract}

Keywords: 2-trifluoromethylacrylate, hexafluoroisopropanol, radical copolymerization, reactivity ratios, copolymerization kinetics, terminal model, penultimate model, dissolution kinetics, quartz crystal microbalance, chemical amplification, $157 \mathrm{~nm}$ lithography

\section{Introduction}

Photolithography continues to evolve, migrating to a shorter wavelength for higher resolution and thus remaining as the dominant microlithographic technology for device manufacturing. Although $157 \mathrm{~nm}\left(\mathrm{~F}_{2}\right.$ excimer laser) lithography emerging as the most promising next generation technology may be an extension of the current 248 and maturing $193 \mathrm{~nm}$ technologies, innovative new resist materials are required as the existing hydrocarbon resist polymers are simply too absorbing at $157 \mathrm{~nm}$ [1]. Only fluoropolymers and silsesquioxane polymers provide low enough absorption at $157 \mathrm{~nm}$. Thus, single layer $157 \mathrm{~nm}$ resists must be built on fluoro-polymers, incorporating other requisite functionalities such as acid-catalyzed deprotection, aqueous base developability, adhesion, dry etch resistance, etc.

Others and we have identified hexafluoroisopropanol (HFA) as a new acidic group which has a $\mathrm{pK}_{\mathrm{a}}$ similar to that of phenol and 2trifluoromethylacrylic unit as 157 -nm-transparent building blocks (Scheme I) [2,3]. The HFA group can be attached to norbornene (NB) or styrene (ST) [2]. We have proposed four platforms for $157 \mathrm{~nm}$ resist systems (Scheme I) [2]. 4(1,1,1,3,3,3-Hexafluoro-2-hydroxypropyl)styrene (STHFA) can be copolymerized by radical initiation with $t$-butyl 2-trifluoromethylacrylate (TBTFMA) and with $t$-butyl methacrylate (TBMA) to form $\mathrm{PF}^{2}$-ESCAP and PF-ESCAP, respectively $[2,4]$. Because $\mathrm{PF}^{2}$-ESCAP is more 
transparent than PF-ESCAP at $157 \mathrm{~nm}$ (3.2-3.6 vs. 4.0-4.2/ $\mu \mathrm{m})$, we have placed more emphasis on $\mathrm{PF}^{2}$-ESCAP, while others have produced good images in PF-ESCAP also [5]. The all-norbornene aliphatic polymers are prepared by transitionmetal-mediated addition polymerization at Promerus. We are more interested in an ESCAPtype system (HFA-ester) than an APEX-type system (HFA-tBOC, $\mathrm{OD}_{157}=2.2-2.5 / \mu \mathrm{m}$ ) because the dissolution rate of the fully exposed area $\left(R_{\max }\right)$ is dictated by HFA in the latter, failing to provide a high developer contrast, while the former employs dissolution acceleration by generation of carboxylic acid. The other aliphatic platform we have been working on is based on a copolymer of TBTFMA with $\alpha, \alpha$-bis-(trifluoromethyl)bicyclo[2.2.1] hept-5-ene-2-ethanol (NBHFA) with a good OD of $2.6 / \mu \mathrm{m}$, which can be prepared by radical copolymerization (Scheme II) [2]. Because this radical copolymerization of two monomers that are very sluggish in homopolymerization is quite unique, providing compositions of TBTFMA/NB $\approx 2 / 1$, and because it is important to understand how copolymers are formed and what kinds of sequence distributions can be expected, we investigated the copolymerization mechanism in detail by determining monomer reactivity ratios and by analyzing the kinetics in situ by ${ }^{1} \mathrm{H} \mathrm{NMR}$, which is briefly reported in this paper. A new aliphatic platform based on radical copolymerization of TBTFMA and vinyl ether derivatives is also described. Furthermore, a new formulation strategy to control the hydrophobicityhydrophilicity balance of the copolymer systems for better lithographic performance is described, which takes advantage of a low OD $(1.7 / \mu \mathrm{m}$ at 157 $\mathrm{nm}$ and $0.04 / \mu \mathrm{m}$ at $193 \mathrm{~nm}$ ) and aqueous base solubility of a NBHFA homopolymer. Our fluoropolymers can function as a dissolution inhibitor of PNBHFA

\section{Experimental}

\subsection{Materials}

2-Trifluoromethylacrylic acid (TFMAA), TBTFMA, NBHFA, and STHFA were prepared according to the previously described procedure [2]. 1-Methylcyclopentyl 2trifluoromethylacrylate (MCPTFMA) was synthesized in a fashion similar to TBTFMA. Other monomers such as TBMA, NB, ethyl vinyl ether (EVE), $t$-butyl vinyl ether (TBVE), 2,3dihydrofuran (DHF), 3,4-dihydro-2- $H$-pyran (DHP), and vinylene carbonate (VCARB) were
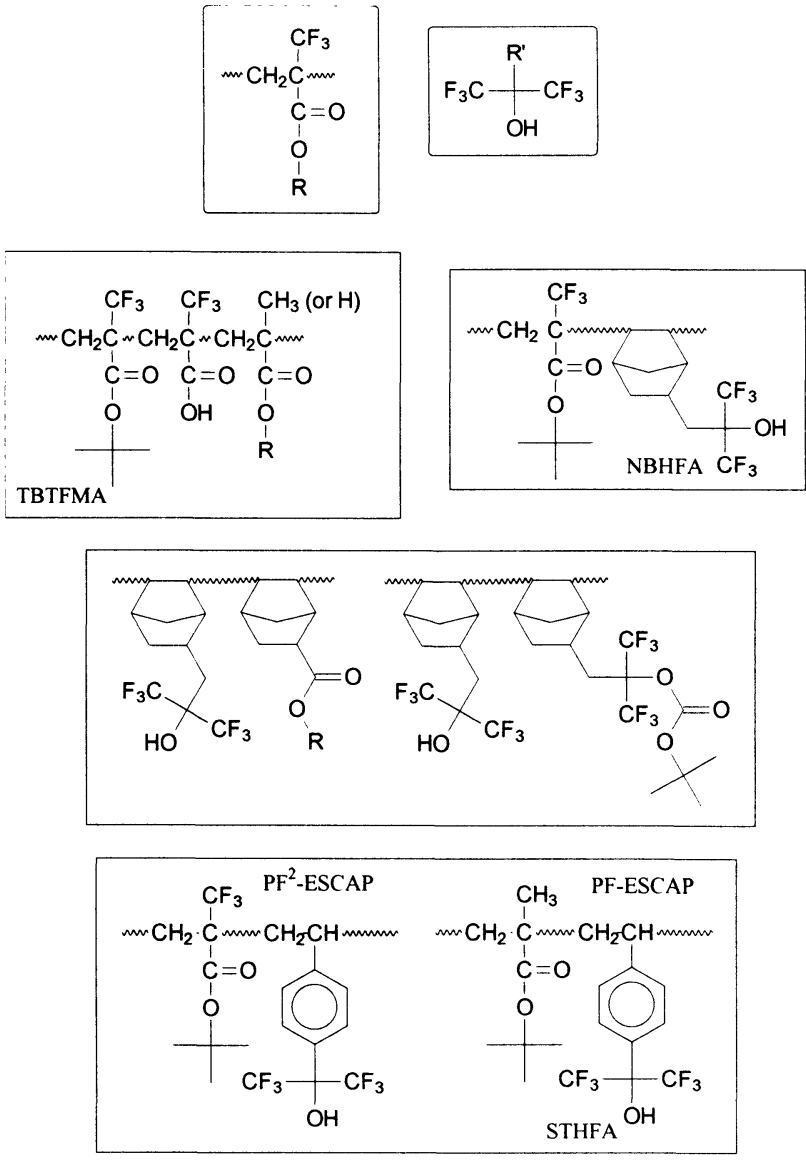

Scheme I

obtained from commercial sources. Homopolymers of NBHFA (PNBHFA) were prepared using a $\mathrm{Pd}$ catalyst at Promerus LLC(formerly BF Goodrich). The casting solvent employed was primarily propylene glycol methyl ether acetate (PGMEA) but cyclohexanone was used in one case. The $0.26 \mathrm{~N}$ tetramethylammonium hydroxide (TMAH) developer employed was CD-26 or LDD26W.

\subsection{Radical Polymerization}

Radical copolymerizations of 2-trifluoromethylacrylic monomers $\left(\mathrm{M}_{1}\right)$ with NB derivatives and vinyl ethers were carried out at $60-75{ }^{\circ} \mathrm{C}$ in $\mathrm{N}_{2}$, after deaeration, with 2,2'-azobis(isobutyronitrile) (AIBN) as the initiator in bulk or in ethyl acetate (EtOAc), tetrahydrofuran (THF), or 1,4-dioxane. The copolymers were purified by repeating precipitation in appropriate solvent and dried in a vacuum oven at $60{ }^{\circ} \mathrm{C}$ overnight. P(TBTFMA-NBHFA) for lithographic evaluation was prepared by copolymerizing TBTFMA and NBHFA (1/1 and $2 / 1$ feed ratios) using $4 \mathrm{~mol} \%$ AIBN in bulk at $60^{\circ} \mathrm{C}$. P(TFMAA-NBHFA) and terplolymers of TBTFMA, TFMAA, and NBHFA 
were also made in a similar fashion for dissolution studies.

For determination of monomer reactivity ratios, copolymerizations were carried out to low conversions (typically $<15 \%$ ), widely changing the feed ratio. Copolymer compositions were determined by ${ }^{19} \mathrm{~F}$ NMR and/or inverse-gated ${ }^{1} \mathrm{H}$ decoupled ${ }^{13} \mathrm{C}$ NMR. The data were first analyzed by the Kelen-Tüdös linear graphic method [6] and by the non-linear least square-procedure [7] on the basis of the terminal model with two reactivity ratios, which gave a very poor fit. Therefore, the copolymerizations were treated by the penultimate model requiring four reactivity ratios.

\section{3. in situ ${ }^{1} \mathrm{H}$ NMR Analysis of Copolymerization Kinetics}

The kinetics of radical copolymerization was monitored in situ at $60-70{ }^{\circ} \mathrm{C}$ by $300 \mathrm{MHz}{ }^{1} \mathrm{H}$ NMR (Bruker AC300) using AIBN as the initiator and $p$-dioxane- $\mathrm{d}_{8}$ as a polymerization and NMR solvent in a fashion similar to the procedures reported previously $[8,9]$.

\subsection{Measurements}

${ }^{1} \mathrm{H}$ and ${ }^{13} \mathrm{C}$ NMR spectra were obtained at room temperature on a Bruker AF250 or Avance 400 spectrometer. Quantitative ${ }^{13} \mathrm{C}$ NMR was run at room temperature in acetone- $\mathrm{d}_{6}$ in an inversegated ${ }^{1} \mathrm{H}$-decoupled mode using $\mathrm{Cr}(\mathrm{acac})_{3}$ as a relaxation agent on a Bruker AF250, AM500, or Avance 400 spectrometer. For polymer composition analysis ${ }^{19} \mathrm{~F}$ NMR (379 MHz) spectra were also obtained using a Bruker Avance 400 spectrometer. Thermo-gravimetric analysis (TGA) was performed at a heating rate of $5{ }^{\circ} \mathrm{C} / \mathrm{min}$ in $\mathrm{N}_{2}$ on a TA Instrument Hi-Res TGA 2950 Thermogravimetric Analyzer. Differential scanning calorimetry (DSC) was performed at a heating rate of $10{ }^{\circ} \mathrm{C} / \mathrm{min}$ on a TA Instruments DSC 2920 modulated differential scanning calorimeter. Molecular weights of the polymers were measured in THF on a Waters Model 150 chromatograph relative to polystyrene standards. IR spectra were recorded on a Nicolet 510 FT-IR spectrometer on a film cast on a $\mathrm{KBr}$ plate. UV measurements at $157 \mathrm{~nm}$ were performed using a Varian Cary Model 400 spectrometer on multiple thickness on $\mathrm{CaF}_{2}$ discs. Film thickness was measured on a Tencor alpha-step 2000. A quartz crystal microbalance (QCM) was used to study the dissolution kinetics of the copolymer films in an aqueous TMAH solution (CD-26) in a fashion similar to the reported procedure [10-12]. Contact angles were measured on an AST Products VCA $2500 \mathrm{XE}$ video contact angle system using $2 \mu \mathrm{L}$ of filtered deionized water.

\subsection{Lithographic Characterization}

Lithographic imaging was carried out on an ISI $193 \mathrm{~nm}$ mini-stepper with a chrome-on-glass mask (COG) and then on an Exitech $157 \mathrm{~nm}$ stepper (at SEMATECH) using an alternating phase shift mask (PSM).

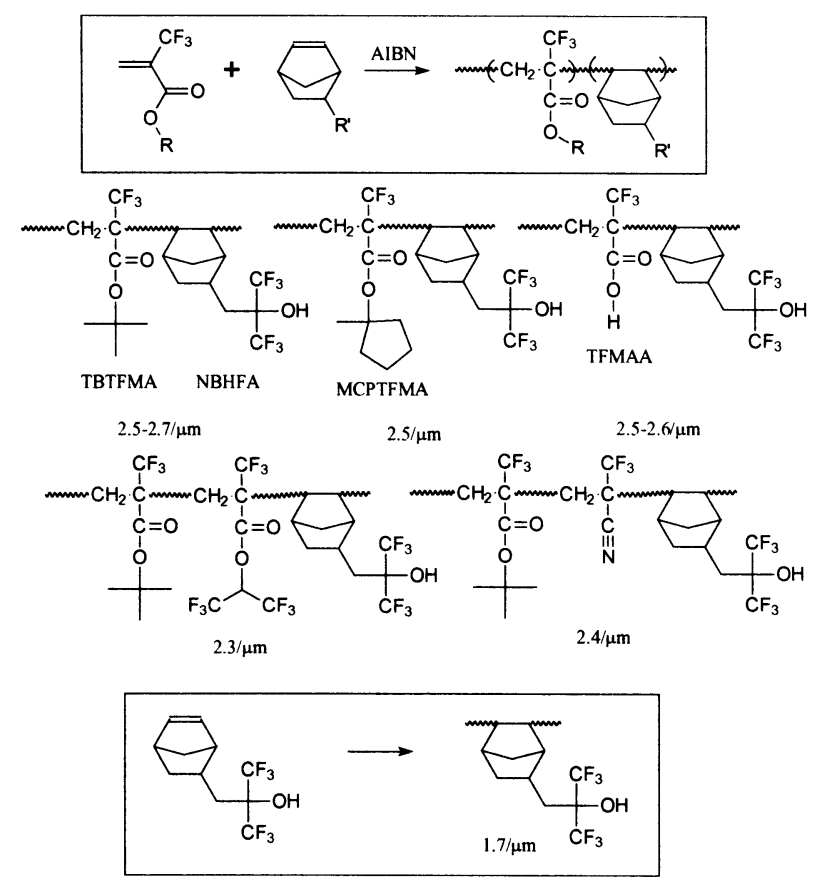

Scheme II

\section{Results and Discussion}

3.1. Radical Copolymerization of 2-Trifluoromethylacrylic Monomers with Norbornene Derivatives

Electron-deficient 2-trifluoromethylacrylic monomers (Alfrey-Price e value for methyl 2trifluoromethylacrylate is 2.5 [13]) and electronrich norbornene derivatives undergo radical copolymerization with a common initiator such as AIBN (Scheme II) [2], although neither monomer produces homopolymer under normal radical polymerization conditions [14]. The copolymer composition has been found to be acrylate/norbornene $=\sim 2 / 1$ through quantitative NMR analysis of copolymers and through in situ kinetics analysis by ${ }^{1} \mathrm{H}$ NMR. In an attempt to better understand this novel and unique copolymerization system and the sequence distributions of the copolymers thus produced, which could impact the dissolution behavior and 
lithographic performance, we carried out more kinetics studies and investigated the copolymerization mechanism.

Copolymerization of two monomers, $\mathrm{M}_{1}$ and $\mathrm{M}_{2}$, is commonly expressed by the simplest terminal model, in which only the polymer terminal (ultimate) groups affect the reactivity of the propagating radicals, requiring only two monomer reactivity ratio parameters, $r_{1}=k_{11} / k_{12}$ and $r_{2}=k_{22} / k_{21}$ (Scheme III). However, it became quickly obvious that the copolymerization of 2trifluoro-methylacrylic monomer $\left(\mathrm{M}_{1}\right)$ and norbornenes $\left(\mathrm{M}_{2}\right)$ cannot be treated by the terminal model; the Kelen-Tüdös plot deviated from a linear line and the reactivity ratios derived by the nonlinear least squares method from the terminal model $\left(r_{1}=0.29\right.$ and $\left.r_{2}=0.0\right)$ failed to fit the experimental feed-composition plots as demonstrated in Figure 1 for TBTFMA-NBHFA. In contrast, the copolymer composition curve generated on the basis of the penultimate model $\left(r_{1}=0.08, \quad r_{1}^{\prime}=0.99\right.$, and $\left.r_{2}=r_{2}{ }^{\prime}=0\right)$ showed an excellent agreement with the experimental data. For this study, the copolymerizations were carried out at $60{ }^{\circ} \mathrm{C}$ in bulk. As expected, NBHFA does not self-propagate $\left(r_{2}=r_{2}{ }^{\prime}=0\right.$ and $\left.k_{222}=k_{122}=0\right)$. The NBHFA monomer reacts with the TBTFMA polymer radical twelve times $(1 / 0.08)$ faster than TBTFMA when the penultimate group is TBTFMA while the TBTFMA monomer adds to the TBTFMA polymer radical as fast as NBHFA when the penultimate group is NBHFA. The penultimate effect is large $\left(\mathrm{r}_{1}{ }^{\prime} / \mathrm{r}_{1}=\sim 12\right)$. Our in situ kinetics studies have indicated that the exo isomer of NBHFA is slightly more reactive than the endo isomer in the TBTFMA-NBHFA copolymerization. We have observed a large penultimate effect also in other monomer combinations. For example, the best penultimate model reactivity ratios we obtained for copolymerization of TBTFMA and NB at $60^{\circ} \mathrm{C}$ in EtOAc were $r_{1}=0.17, r_{1}{ }^{\prime}=1.91$, and $r_{2}=r_{2}{ }^{\prime}=0$ $\left(r_{1}{ }^{\prime} / r_{1}=11\right)$. In this case TBTFMA reacts twice faster with the TBTFMA polymer radical than NB when the penultimate group is NB. The NB monomer reacts with the TBTFMA polymer radical six times $(1 / 0.17)$ faster than TBTFMA when the penultimate group is TBTFMA. Thus, TBTFMA can form a trimer $\left(\mathrm{k}_{111} \neq 0\right)$ while its radical homopolymerization is very sluggish [14].

We have observed a penultimate effect and addition of TBTFMA to its polymer radical in copolymerization with STHFA also. The
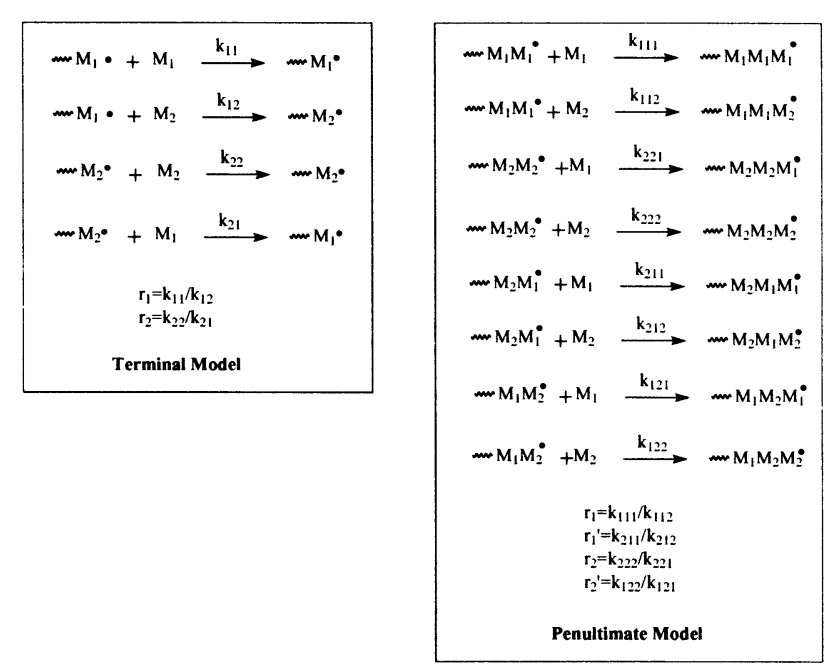

Scheme III

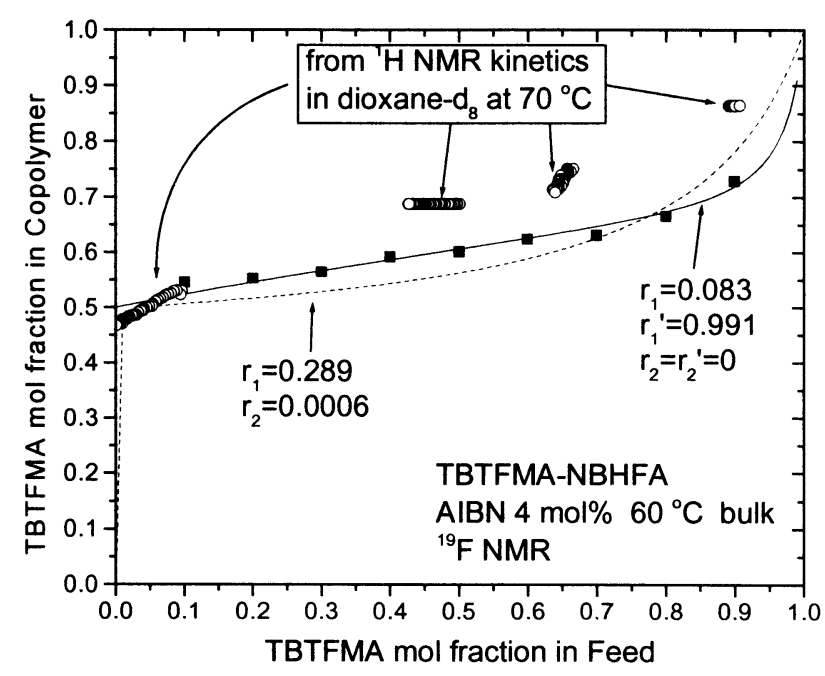

Figure 1 Copolymer composition curves for TBTFMA-NBHFA

copolymerization of TBTFMA $\left(\mathrm{M}_{1}\right)$ and STHFA $\left(\mathrm{M}_{2}\right)\left(\mathrm{PF}^{2}\right.$-ESCAP) with AIBN at $75^{\circ} \mathrm{C}$ in EtOAc appeared to follow the terminal model, providing a fairly linear Kelen-Tüdös plot $\left(r_{1}=0.000\right.$ and $\mathrm{r}_{2}=0.418$ ) and the composition curve constructed on the reactivity ratio values determined by the nonlinear least-square method $\left(r_{1}=0.000\right.$ and $\left.r_{2}=0.426\right)$ agreed quite well with the experimental data. However, a penultimate model with $r_{1}=r_{1}{ }^{\prime}=0, r_{2}=0.32$, and $r_{2}{ }^{\prime}=0.60$ provided a better fit. Furthermore, by allowing TBTFMA to react slowly with a TBTFMA polymer radical when the penultimate unit is STHFA $\left(\mathrm{r}_{1}^{\prime}=0.01\right)$, the experimental data can be almost perfectly interpreted by the penultimate model involving four different reactivity ratio values as 
demonstrated in Figure 2. The copolymer compositions were determined by ${ }^{19} \mathrm{~F}$ NMR in this case as well as by inverse-gated ${ }^{1} \mathrm{H}$-decoupled ${ }^{13} \mathrm{C}$ NMR. In the presence of reactive styrene, TBTFMA adds to a TBTFMA polymer radical occasionally only when the penultimate unit is STHFA $\left(\mathrm{k}_{211} \neq 0\right)$ while a three consecutive TBTFMA sequence does not form $\left(\mathrm{k}_{111}=0\right)$. When the comonomer is less reactive as is the case with norbornene derivatives, TBTFMA can have a sequence length of three. We have found by in situ ${ }^{1} \mathrm{H}$ NMR analysis of kinetics that even in the case of the TBTFMA-STHFA copolymerization, a longer sequence of TBTFMA is produced when

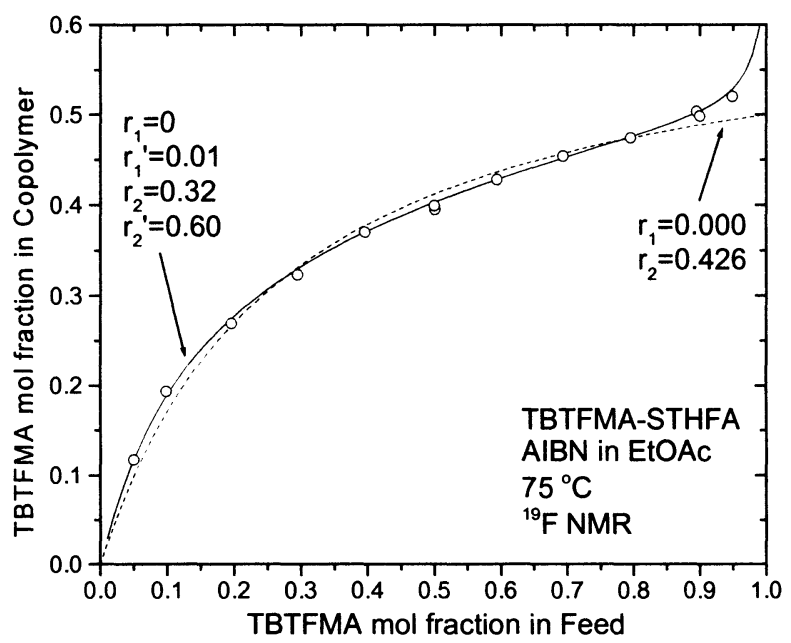

Figure 2 Copolymer composition curves for TBTFMA-STHFA

more reactive STHFA is exhaustively consumed (as is the case with a feed ratio of TBTFMA/STHFA=90/10). In fact, in situ monitoring of AIBN decomposition, recombination of primary radicals generated from AIBN (waste process), and consumption of TFMAA (without comonomer) has revealed that the catalytic chain length of TFMAA is 2.5-2.7 at any given time of the reaction involving TFMAA and AIBN at $75{ }^{\circ} \mathrm{C}$ in dioxane- $\mathrm{d}_{8}$. TFMAA was employed in this kinetics run without a comonomer because the $\mathrm{CH}_{3}{ }^{1} \mathrm{H}$ NMR resonances of AIBN and tetramethylsuccinodinitrile (primary radical recombination) can be observed without interference from the monomer or oligomer. This kinetics study completely agrees with the penultimate model for the copolymerization involving 2-trifluoromethylacrylic monomers; TBTFMA or 2-trifluoromethylacrylic monomers can self-propagate to a trimer but do not homopolymerize in a practical sense. In contrast, radical copolymerization of TBMA $\left(\mathrm{M}_{1}\right)$ with STHFA $\left(\mathrm{M}_{2}\right)$ (PF-ESCAP) can be nicely interpreted by the terminal model $\left(r_{1}=0.458\right.$ and $\mathrm{r}_{2}=0.841$ by the nonlinear least-square method, $\mathrm{r}_{1}=0.478$ and $\mathrm{r}_{2}=0.905$ by the Kelen-Tüdös method) and is thus similar to ESCAP [8].

We have simulated several copolymerization systems on the basis of the penultimate model and calculated feed and copolymer compositions, sequence distributions (triads, pentads, and heptads), etc. as a function of the feed ratio and conversion. Quantification of the triad sequences should provide us with a way to distinguish between the terminal, penultimate, and complex models. Unfortunately, however, ${ }^{13} \mathrm{C}$ and $\alpha-\mathrm{CF}_{3}$ ${ }^{19} \mathrm{~F}$ NMR resonances of the copolymers exhibit much more complex splitting, which may reflect influence of other factors than the comonomer sequence distribution, and thus cannot be explained by simple triad sequences (a NBHFA copolymer shown in Figure 3).

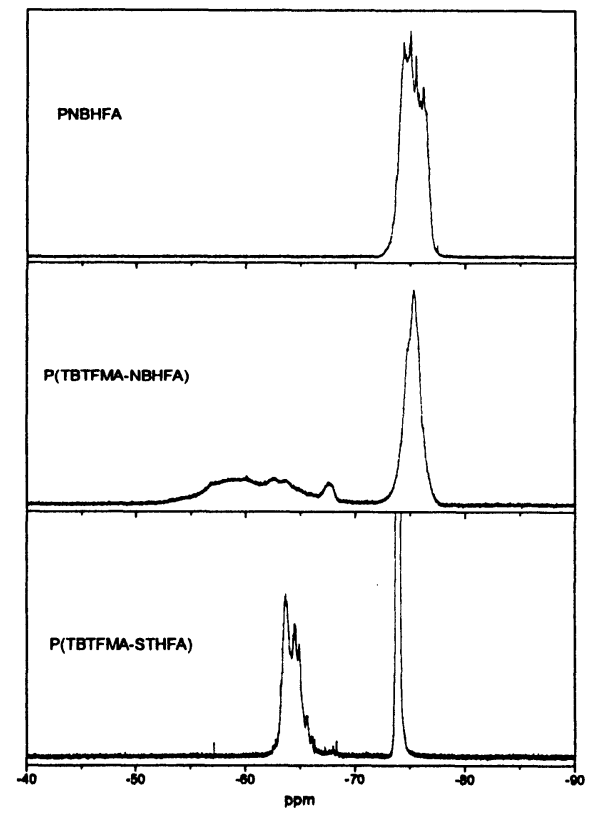

Figure $3{ }^{19} \mathrm{~F}$ NMR spectra of PNBHFA, P(TBTFMA-NBHFA), and $P\left(\right.$ TBTFMA-STHFA) in acetone- $\mathrm{d}_{6}$

From analysis of copolymerization kinetics in situ by ${ }^{1} \mathrm{H}$ NMR monomer concentrations $\left(\left[\mathrm{M}_{1}\right]\right.$ and $\left.\left[\mathrm{M}_{2}\right]\right)$, feed composition, cumulative copolymer composition, conversion, etc. can be plotted as a function of polymerization time for a given initial feed ratio [8,9]. Furthermore, $\left[\mathrm{M}_{1}\right]$ can be plotted as a function of $\left[\mathrm{M}_{2}\right]$ (Figure 4 ). The 
composition of copolymer instantaneously produced at a given moment can be obtained from the slope $\left(d\left[M_{1}\right] / d\left[M_{2}\right]\right)$ of the $\left[M_{1}\right]-\left[M_{2}\right]$ plot, and thus a copolymer composition curve (only partial depending on the feed ratio change) such as the ones shown in Figure 1 can be constructed. For example, in the case of 1:1 TBTFMA-NBHFA copolymerization at $70{ }^{\circ} \mathrm{C}$ in dioxane- $\mathrm{d}_{8}$, the TBTFMA concentration in the feed changes from 50 to $43 \mathrm{~mol} \%$ while the instantaneous copolymer composition remains almost constant at TBTFMA/NBHFA=69/31 for $20 \mathrm{hrs}$ (Figure 1). Instantaneous incorporation of TBTFMA in copolymer is higher in dioxane- $\mathrm{d}_{8}$ (also more dilute) at $70{ }^{\circ} \mathrm{C}$ than in bulk at $60{ }^{\circ} \mathrm{C}$, suggesting influence of solvent on the penultimate effect. More details will be reported elsewhere.

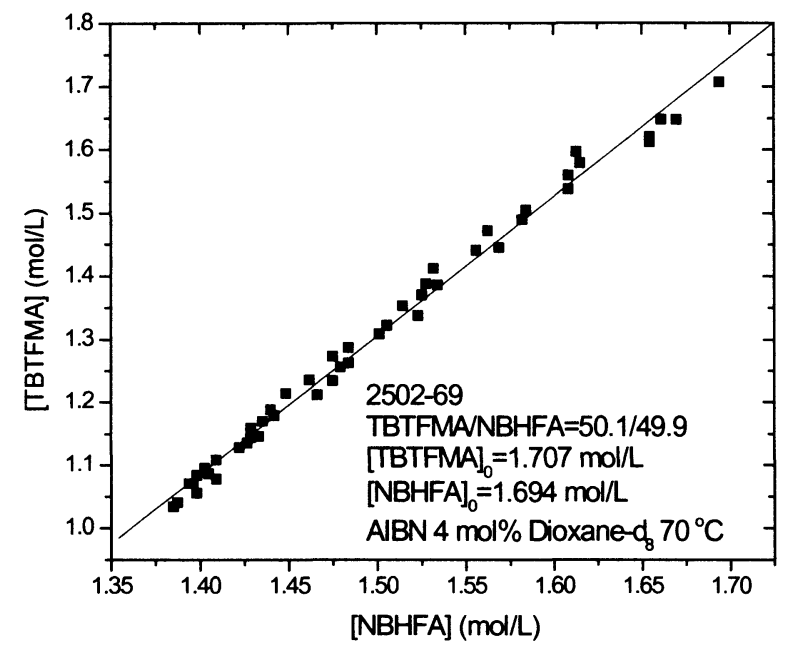

Figure 4 Change of monomer concentrations in copolymerization of TBTFMA and NBHFA as determined by ${ }^{1} \mathrm{H}$ NMR

3.2. Radical Copolymerization of 2-Trifluoromethylacrylic Monomers with Vinyl Ether Derivatives

Monomer consumption kinetics curves for radical copolymerization of methyl 2trifluoromethylacrylate (MTFMA) and DHP in dioxane- $d_{8}$ at $70{ }^{\circ} \mathrm{C}$ are presented in Figure 5. Vinyl ethers can copolymerize with 2trifluoromethylacrylic monomers by a radical mechanism, providing a new platform for the resist design. The $193 \mathrm{~nm}$ VEMA polymers are prepared by radical copolymerization of vinyl ethers with maleic anhydride [15]. In this case the MTFMA concentration in copolymer is about 70 mol\%, independent of conversion, and the copolymer yield is about $60 \mathrm{wt} \%$ after $27 \mathrm{hrs}$. In
Scheme IV and Table 1 are summarized some of the vinyl ether derivatives employed in radical copolymerization with 2-trifluoromethylacrylic monomers and copolymerization conditions. Copolymer properties are summarized in Table 2. TBVE copolymerized with TBTFMA very rapidly and the polymerization mixture completely solidified in bulk within $5 \mathrm{~min}$, producing a high molecular weight polymer. High dilution with EtOAc still resulted in a fast high-yield copolymerization ( $87 \%$ yield in $28 \mathrm{hrs)}$ to a high molecular weight polymer $\left(\mathrm{M}_{\mathrm{n}}=55,100\right.$ and $\mathrm{M}_{\mathrm{w}}=237,300$ ). A copolymer containing a slight excess of TBTFMA (51-52 mol\%) was obtained from TBTFMA/TBVE $=1 / 1$ in initial feed. EVE copolymerized well with TBTFMA in solution, producing a high molecular weight copolymer in a high yield. The copolymer composition was TBTFMA/EVE $=65 / 35$ from a 1:1 feed in this case. Like DHP (Figure 5), cyclic DHF underwent radical copolymerization with TBTFMA in bulk, providing a high yield of $82 \%$ in $23 \mathrm{hrs}$. The copolymer contained $58 \mathrm{~mol} \%$ of TBTFMA. The molecular weights were rather low $\left(\mathrm{M}_{\mathrm{n}}=2,700\right.$ and $\left.\mathrm{M}_{\mathrm{w}}=4,100\right)$ perhaps due to chain transfer and steric hindrance. Furthermore, VCARB, a cyclic carbonate, has been found to copolymerize with TBTFMA, yielding a copolymer containing 43 mol\% VCARB with decent molecular weights $\left(M_{n}=6,000\right.$ and $\left.M_{w}=10,000\right)$, although the yield was rather low (23\%). Detailed reactivity and kinetics analyses are in progress.

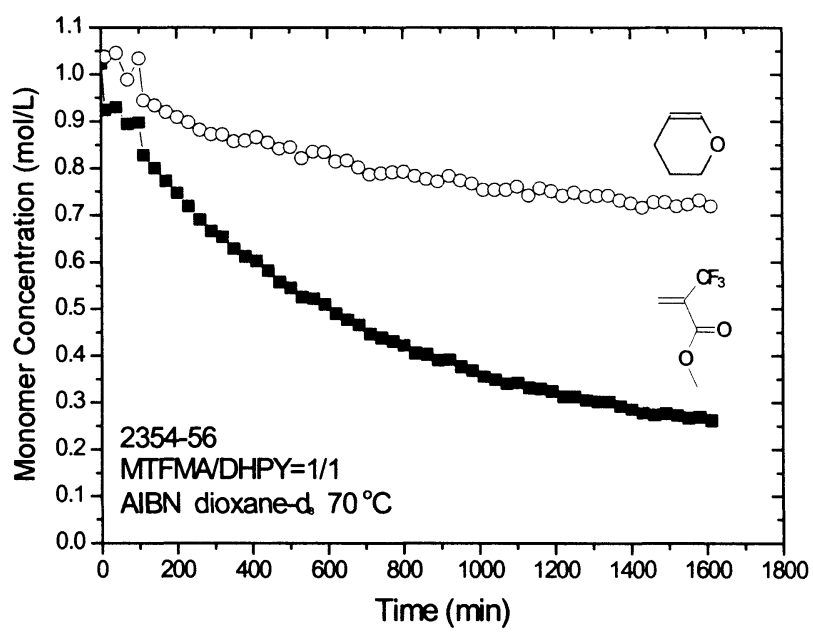

Figure 5 Monomer consumption kinetics in radical copolymerization of MTFMA with DHP at $70^{\circ} \mathrm{C}$ in dioxane- $\mathrm{d}_{8}$ 


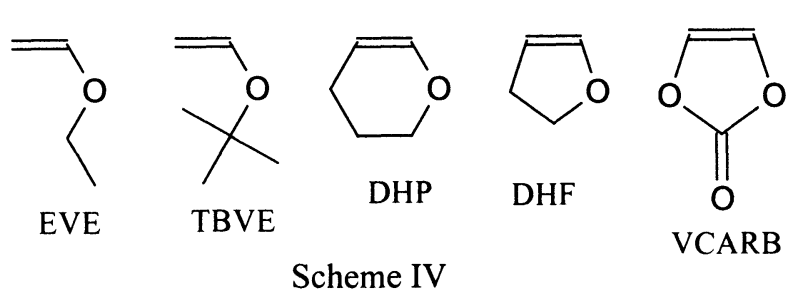

Table 1 Radical copolymerization of TBTFMA and vinyl ether derivatives with $4 \mathrm{~mol} \%$ AIBN at $60^{\circ} \mathrm{C}$

\begin{tabular}{|l|l|r|r|r|r|}
\hline \multicolumn{1}{|c|}{$\begin{array}{c}\mathrm{M}_{1} \\
(\mathrm{~mol})\end{array}$} & \multicolumn{1}{|c|}{$\begin{array}{c}\mathrm{M}_{2} \\
(\mathrm{~mol})\end{array}$} & \multicolumn{1}{c|}{ Solv } & \multicolumn{1}{c|}{$\begin{array}{c}\text { Time } \\
(\mathrm{hr})\end{array}$} & $\begin{array}{c}\text { Yield } \\
(\%)\end{array}$ & \multicolumn{1}{c|}{$\begin{array}{c}\text { Polymer } \\
\text { Comp. }\end{array}$} \\
\hline $\begin{array}{l}\text { TBTFMA } \\
(0.05)\end{array}$ & $\begin{array}{l}\text { TBVE } \\
(0.05)\end{array}$ & & $\begin{array}{l}<5 \\
\text { min }\end{array}$ & $>49$ & $52 / 48$ \\
\hline $\begin{array}{l}\text { TBTFMA } \\
(0.05)\end{array}$ & $\begin{array}{l}\text { TBVE } \\
(0.05)\end{array}$ & $\begin{array}{l}\text { EtOAc } \\
(30 \mathrm{~g})\end{array}$ & 28 & 87 & $51 / 49$ \\
\hline $\begin{array}{l}\text { TBTFMA } \\
(0.05)\end{array}$ & $\begin{array}{l}\text { EVE } \\
(0.05)\end{array}$ & $\begin{array}{l}\text { EtOAc } \\
(41 \mathrm{~g})\end{array}$ & 42 & 80 & $65 / 35$ \\
\hline $\begin{array}{l}\text { TBTFMA } \\
(0.05)\end{array}$ & $\begin{array}{l}\text { DHF } \\
(0.05)\end{array}$ & & 23 & 82 & $58 / 42$ \\
\hline $\begin{array}{l}\text { TBTFMA } \\
(0.05)\end{array}$ & $\begin{array}{l}\text { VCARB } \\
(0.05)\end{array}$ & & 24 & 23 & $57 / 43$ \\
\hline
\end{tabular}

Table 2 Properties of TBTFMA-vinyl ether copolymers

\begin{tabular}{|r|r|r|r|r|}
\hline $\begin{array}{r}\text { Polymer } \\
\text { Composition }\end{array}$ & $\mathrm{Mn}$ & $\mathrm{Mw}$ & $\begin{array}{c}\mathrm{Tg} \\
\left({ }^{\circ} \mathrm{C}\right)\end{array}$ & $\begin{array}{c}\mathrm{OD}_{157} \\
\left(\mu \mathrm{m}^{-1}\right)\end{array}$ \\
\hline $\begin{array}{r}\text { TBTFMA/TBVE }= \\
52 / 48\end{array}$ & 50,930 & 268,580 & 122 & \\
\hline $\begin{array}{r}\text { TBTFMA/EVE }= \\
51 / 49\end{array}$ & 55,130 & 237,300 & 125 & $3.7-3.8$ \\
\hline $\begin{array}{r}\text { TBTFMA/EVE } \\
65 / 35\end{array}$ & 80,300 & 181,800 & 66 & $3.3-3.6$ \\
\hline $\begin{array}{r}\text { TBTFMA/DHF }= \\
58 / 42\end{array}$ & 2,730 & 4,080 & 89 & 3.8 \\
\hline $\begin{array}{r}\text { TBTFMA/VCARB } \\
=57 / 43\end{array}$ & 5,980 & 10,020 & & $4.2-4.5$ \\
\hline
\end{tabular}

\subsection{Copolymer Compositions and Microstructures}

The composition of P(TBTFMA-NBHFA) and $P($ TBTFMA-STHFA) containing fluorine in each repeat unit can be conveniently determined by ${ }^{19} \mathrm{~F}$ NMR (Figure 3). Integration of the two wellseparated signals at about $-75 \mathrm{ppm}\left(2\right.$ pendant $\mathrm{CF}_{3}$ groups in fluoroalcohol) and in the range of -50 to $-70 \mathrm{ppm}\left(\alpha-\mathrm{CF}_{3}\right.$ of the TBTFMA unit) can directly determine the composition. The pendant $\mathrm{CF}_{3}$ group gives a sharper resonance than the $\alpha-$ $\mathrm{CF}_{3}$ linked to the backbone due to greater mobility in the copolymers. It is interesting to note, however, that the $F$ resonances of the NBHFA copolymer are much broader than those of the STHFA copolymer. The TBTFMA-STHFA copolymer is likely to consist of head-to-tail linkages and the splitting in the $\alpha-\mathrm{CF}_{3}$ resonance primarily reflects sequence distributions (and stereoregularity). The pendant $\mathrm{CF}_{3}$ group may not be sensitive to the long range interactions and thus gives rise to a sharp singlet peak. In the case of P(TBTFMA-NBHFA), the $\mathrm{CF}_{3}$ group pendant from the ring gives a much broader resonance than in the aromatic copolymer. Several explanations may be possible. The $\mathrm{CF}_{3}$ group in the aliphatic copolymer may be sensitive to stereoregularities and/or sequence distributions. The isomeric structures of NBHFA (endo and exo) could give rise to a broader resonance. Furthermore, the two $\mathrm{CF}_{3}$ groups in each isomer are magnetically nonequivalent (prochiral) due to the chiral center on the 5-position of the ring and exhibit two sets of ${ }^{19} \mathrm{~F}$ resonances for each isomer. The two $\mathrm{CF}_{3}$ quartet resonances at $376.5 \mathrm{MHz}$ of the endo isomer are separated by as much as $1 \mathrm{ppm}$ while the exo isomer provides more equivalent magnetic environment to the $\mathrm{CF}_{3}$ groups $(0.12 \mathrm{ppm}$ separation). The two $\mathrm{CF}_{3}$ groups of STHFA are magnetically equivalent, giving rise to a single peak. In addition, a polymer radical could react with either $\alpha$ or $\beta$ carbon of the vinylene double bonds in 5-substituted norbornene, resulting in head-to-tail, head-to-head, and tail-to-tail linkages. All these factors could contribute to broadening of the resonance. It is interesting that a simple homopolymer of NBHFA prepared with a Pd catalyst exhibits a broad ${ }^{19} \mathrm{~F}$ resonance with some splitting, suggesting the microstructures involving the factors mentioned above. As a consequence, the $\mathrm{CF}_{3}$ resonance of the TBTFMA unit is affected also by the complex structural variation of the NBHFA units, splitting into many peaks in a wide chemical shift range. The rigid backbone structure of P(TBTFMA-NBHFA) contributes to resonance broadening as well.

Inverse-gated ${ }^{1} \mathrm{H}$-decoupled $62.9 \mathrm{MHz}{ }^{13} \mathrm{C}$ NMR of copolymers of TBTFMA with vinyl ether derivatives in the presence of $\mathrm{Cr}(\mathrm{acac})_{3}$ in acetone$\mathrm{d}_{6}$ are presented in Figure 6. While the TBTFMA concentration in the copolymer varies only slightly from 51 to $65 \mathrm{~mol} \%$, the ester carbonyl, $\alpha-\mathrm{CF}_{3}$, and $t$-butyl ester quaternary carbon resonances exhibit interesting splitting unique to each copolymer.

\subsection{Blending of Copolymers with PNBHFA}

While $\mathrm{PF}^{2}$-ESCAP is hydrophilic due to a high concentration $(>50 \mathrm{~mol} \%)$ of STHFA $[2,4]$, the TBTFMA copolymer with NBHFA is highly hydrophobic due to the high concentration of TBTFMA (60-70 mol\%). Aqueous base developer cannot wet the P(TBTFMA-NBHFA) film (contact angle $87-88^{\circ}$ ) and therefore the copolymer resist 


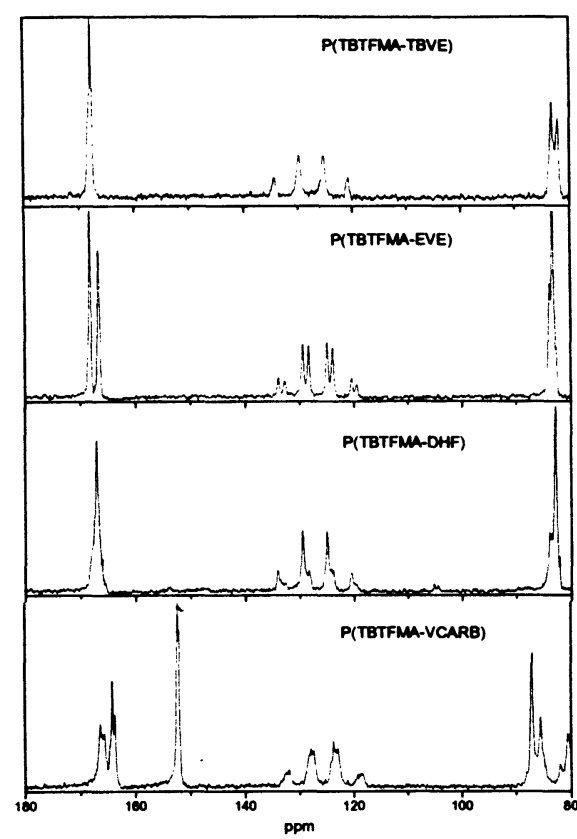

Figure $662.9 \mathrm{MHz}$ Inverse-gated ${ }^{13} \mathrm{C}$ NMR spectra of vinyl ether copolymers with $\mathrm{Cr}(\mathrm{acac})_{3}$ in acetone- $\mathrm{d}_{6}$

does not develop well. Unfortunately, the copolymer composition cannot be changed much by changing the feed ratio (Figure 1). We were not interested in incorporating carboxylic acid using TFMAA as a third comonomer because swelling could become serious. PNBHFA has been found to be homogeneously miscible with P(TBTFMA-NBHFA), certain vinyl ether copolymers, and PF-ESCAP. The stronglyinteracting hexafluoro-isopropanol functionality seems to promote miscibility. The protected lipophilc copolymers can function as a dissolution inhibitor of PNBHFA. Since the NBHFA homopolymer is a major component in our blend resist formulation, we quantified residual PGMEA in a $1.1-\mu \mathrm{m}$-thick PNBHFA film baked at $130^{\circ} \mathrm{C}$ for $60 \mathrm{sec}$ by our inverse-gated ${ }^{13} \mathrm{C}$ NMR technique [16]. The film contained less than 1 wt\% (about 0.4 wt\%) PGMEA, confirming our earlier observation by ${ }^{14} \mathrm{C}$ labeling that fluorinecontaining $157 \mathrm{~nm}$ polymers tend to release solvent rapidly upon baking [4,2c]. Poly(4hydroxystyrene) baked under the same conditions was found to contain $4 \mathrm{wt} \%$ PGMEA by the ${ }^{13} \mathrm{C}$ NMR technique [16].

P(TBTFMA $A_{0.67}-$ NBHFA $\left._{0.33}\right) \quad\left(\mathrm{M}_{\mathrm{n}}=8,300, \mathrm{M}_{\mathrm{w}}=\right.$ $\left.11,000, \mathrm{OD}_{157}=2.7 / \mu \mathrm{m}\right)$ was blended in PGMEA with PNBHFA $\left(\mathrm{M}_{\mathrm{n}}=9,300, \mathrm{M}_{\mathrm{w}}=13,500, \mathrm{OD}_{157}=\right.$ $1.8 / \mu \mathrm{m})$ ) at a $1 / 1,1 / 2$, and $1 / 3$ molar ratio. The blend films cast from PGMEA solution looked uniform without any sign of incompatibility and did not exhibit cracking, peeling, or irregular nonuniform dissolution during aqueous base development. Figure 7 presents the dissolution behavior of the blend films in comparison with PNBHFA as studied by QCM. The copolymers themselves are not shown as they are simply insoluble [2]. While PNBHFA employed in blending dissolved rapidly at 4,500 $\mathrm{A} / \mathrm{sec}$ in CD26, addition of P(TBTFMA-NBHFA) at a $44 / 56$ $\mathrm{wt} / \mathrm{wt}$ ratio completely insolubilized the film in the same developer. The concentration of the copolymer in the blend could be further reduced to $26 \mathrm{wt} \%$, at which the film began to exhibit minor swelling. Thus, a blend containing as much as 74 $w t \%$ PNBHFA could be employed as a resist polymer. Owing to the low absorption of PNBHFA at $157 \mathrm{~nm}(\mathrm{OD}=1.7-1.8 / \mu \mathrm{m})$, such blend films have low OD of $2.5-2.0 / \mu \mathrm{m}$. The lithographically useful $1 / 1$ and $1 / 2$ blends are quite transparent at $157 \mathrm{~nm}(\mathrm{OD}=2.2-2.0 / \mu \mathrm{m})$. This reduction of OD at $157 \mathrm{~nm}$ (also at $193 \mathrm{~nm}$ ) is another important advantage of blending with PNBHFA. PF-ESCAP with a high OD of $>4 / \mu \mathrm{m}$ is miscible with PNBHFA and can function as a dissolution inhibitor. Its OD is reduced to 3.0$2.5 / \mu \mathrm{m}$ by blending. Use of PNBHFA in $193 \mathrm{~nm}$ lithography is also very attractive as it is the most transparent material with an OD of $0.04 / \mu \mathrm{m}$.

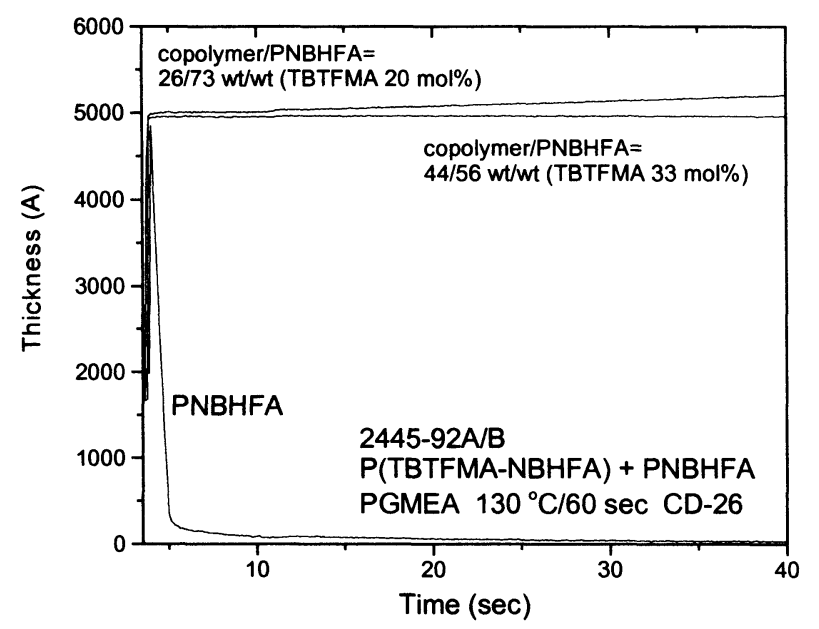

Figure 7 Dissolution kinetics curves of PNBHFA and its blends with P(TBTFMA-NBHFA) in CD-26

The vinyl ether copolymers tend to be hydrophobic and can be best used as a lithographic 
resist material in a blend with hydrophilic PNBHFA (contact angle $70^{\circ}$ ). While the TBTFMA-TBVE copolymer did not mix with PNBHFA even in solution and the TBTFMA-EVE copolymer phase-separated from PNBHFA upon spinning, the copolymers of TBTFMA with DHF and with VCARB formed a homogeneous blend with the NBHFA homopolymer. The blend films (cast from PGMEA for the DHF copolymer and from cyclohexanone for the VCARB copolymer) did not dissolve or swell in $0.26 \mathrm{~N}$ TMAH solution for at least $200 \mathrm{sec}$ even when the blend ratio was copolymer/PNBHFA=1/2. The vinyl ether copolymers have a fairly high OD $(3.3-3.8 / \mu \mathrm{m}$, $4.2-4.5 / \mu \mathrm{m}$ ) because fluorine is not placed in every repeat unit. In addition to the polarity control, the blend approach can reduce the $157 \mathrm{~nm}$ OD significantly. Thus, the TBTFMA-DHF copolymer with OD of $3.8 / \mu \mathrm{m}$ was rendered much more transparent $(2.6 / \mu \mathrm{m})$ by blending it with 2 parts of PNBHFA. Similarly, the OD of the TBTFMA-VCARB copolymer $(4.2-4.5 / \mu \mathrm{m})$ was reduced to $3.2 / \mu \mathrm{m}$ by $1: 2$ blending with PNBHFA. The vinyl ether copolymers have a low glass transition temperature $\left(\mathrm{T}_{\mathrm{g}}\right)$ in general as shown in Table 2, which can be increased to a more desirable range by blending with PNBHFA possessing a high $\mathrm{T}_{\mathrm{g}}$ of $222^{\circ} \mathrm{C}$.

Water contact angles of some copolymer and blend films are summarized in Table 3. The copolymers of 2-trifluoromethylacrylic esters with NBHFA are hydrophobic with a contact angle of about $82^{\circ}$ while the copolymer of 2-trifluoromethylacrylic acid with NBHFA has a low contact angle of $59{ }^{\circ}$. The contact angle of the homopolymer of NBHFA was about $70^{\circ}$. The copolymers of TBTFMA and vinyl ethers are highly hydrophobic $\left(90^{\circ}\right)$. Blending PNBHFA to the hydrophobic copolymers lowers the contact angle by about $10^{\circ}$.

Table $3 \mathrm{H}_{2} \mathrm{O}$ contact angles of copolymers and blends

\begin{tabular}{|c|c|c|}
\hline polymer & $\begin{array}{c}\text { blend } \\
\text { ratio } \\
\text { (wt/wt) }\end{array}$ & $\begin{array}{l}\text { contact } \\
\text { angle }\end{array}$ \\
\hline $\mathrm{P}\left(\mathrm{MCPTFMA}_{0.58}-\mathrm{NBHFA}_{0.42}\right)$ & & 82 \\
\hline $\begin{array}{c}\left.\text { P(MCPTFMA }{ }_{0.58}-\mathrm{NBHFA}_{0.42}\right) / \\
\text { PNBHFA }\end{array}$ & $1 / 1$ & 71 \\
\hline P(TBTFMA ${ }_{0.58}-$ DHF $\left._{0.42}\right)$ & & 90 \\
\hline P(TBTFMA $\left.{ }_{0.58}-\mathrm{DHF}_{0.42}\right) /$ PNBHFA & $1 / 1$ & 81 \\
\hline PNBHFA & & 70 \\
\hline P(TFMAA $_{0.58}-$ NBHFA $\left._{0.42}\right)$ & & 59 \\
\hline $\begin{array}{c}\left.\text { P(TFMAA }_{0.58}-\text { NBHFA }_{0.42}\right) / \\
\text { PNBHFA }\end{array}$ & $1 / 1$ & 69 \\
\hline
\end{tabular}

\subsection{Blend Resist Characterization}

The copolymers of the tertiary ester (TBTFMA and MCPTFMA) with NBHFA are insoluble and P(TFMAA-NBHFA) dissolves very rapidly $(34,700 \mathrm{~A} / \mathrm{sec})$ in $0.26 \mathrm{~N}$ TMAH as reported before [2]. The dissolution rate of PNBHFA employed in the blend study was about $6,000 \mathrm{~A} / \mathrm{sec}$ in CD-26. While the blend of P(TBTFMA-NBHFA) with PNBHFA does not dissolve or swell in CD-26 upto about a 1:2 ratio, full conversion of the $t$-butyl ester to carboxylic acid in the blends results in a fast dissolution rate of 18,000 and $13,000 \mathrm{~A} / \mathrm{sec}$ for the $1: 1$ and $1: 2$ blends, respectively (Figure 8). In order to understand the relationship between the degree of deprotection and dissolution rate of the blend films, P(TBTFMA-NBHFA) and P(TFMAANBHFA) were blended with PNBHFA, keeping the copolymer/PNBHFA molar ratio constant at $1 / 1$ and $1 / 2$ while changing the copolymer ratio. The blend film started dissolving fast upon about $30 \%$ deprotection as demonstrated in Figure 8.

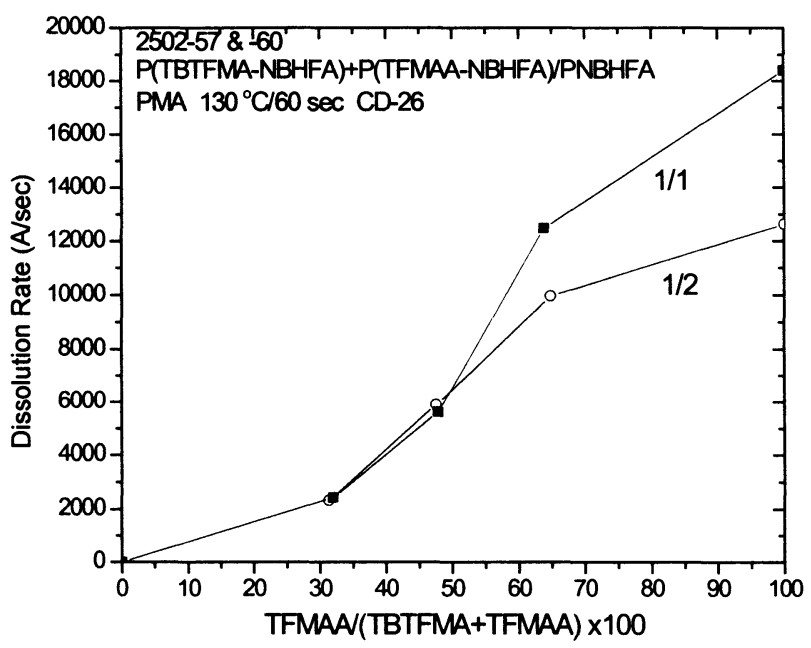

Figure 8 Dissolution rate of ternary blends in $0.26 \mathrm{~N}$ TMAH

As certain photochemical acid generators (PAGs) are strong dissolution inhibitors of phenolic resins and function like a diazonaphtoquinone (the expsoed area dissolves faster $[11,17,18])$, the effect of PAG addition on the dissolution rate of PNBHFA was investigated. Di-4-t-butyl-diphenyliodonium perfluorooctanesulfonate (IPFOS) was added at $4 \mathrm{wt} \%$ to PNBHFA in PGMEA. Spin-cast films were baked at $130{ }^{\circ} \mathrm{C}$ for $60 \mathrm{sec}$ and their dissolution rates in CD-26 were measured by QCM (Figure 9). PNBHFA by itself dissolved at $4,465 \mathrm{~A} / \mathrm{sec}$. The 
PNBHFA/IPFOS binary film exhibited more complex dissolution kinetics; intial swelling, linear dissolution at $746 \mathrm{~A} / \mathrm{sec}$, and fast dissolution of an interfacial layer at 3,009 $\mathrm{A} / \mathrm{sec}$ [19]. In any events, the addition of IPFOS to PNBHFA resulted in significant reduction of the dissolution rate $(4,465$ to $746 \mathrm{~A} / \mathrm{sec})$. Exposure of the binary film on Au substrate to $40 \mathrm{~mJ} / \mathrm{cm}^{2}$ of $193 \mathrm{~nm}$ radiation reduced the intial swelling a little but did not alter the overall dissolution behavior, though strong standing wave patterns were observed. Postexpsoure-bake (PEB) at $130{ }^{\circ} \mathrm{C}$ annealed out the standing wave patterns a little and further reduced the swelling but did not affect the dissolution rate in a significant way. IPFOS inhibits the dissolution of PNBHFA in aqueous base but its photochemical conversion to acid does not appear to affect the dissolution rate significantly. More studies are under way.

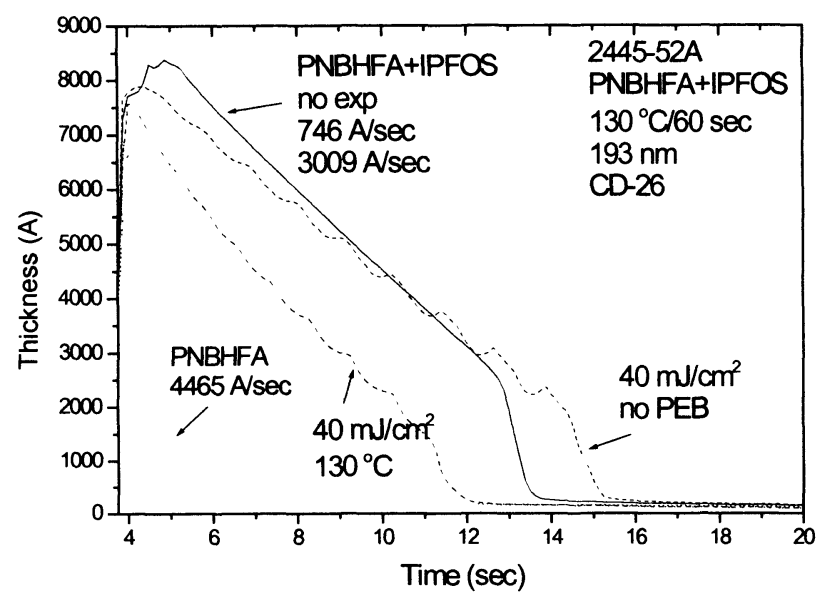

Figure 9 Dissolution kinetics of PNBHFA/IPFOS

The positive effect of the blending on lithographic performance is dramatically illustrated by the contrast curves in Figure 10 . Two formulations were prepared by adding $4 \mathrm{wt} \%$ of IPFOS and a quencher to P(TBTFMA-NBHFA) and its 1:1 blend with PNBHFA in PGMEA. The films were baked at $130{ }^{\circ} \mathrm{C}$ for $60 \mathrm{sec}$, exposed to $193 \mathrm{~nm}$ radiation, postexposure-baked at $140{ }^{\circ} \mathrm{C}$ for $60 \mathrm{sec}$, and developed with LDD26W for 60 sec. Thinning occurred in the exposed area due to acid-catalyzed deprotection. However, the copolymer resist film did not develop at all in LDD26W. In contrast, the blend resist exhibited a good development characteristic.

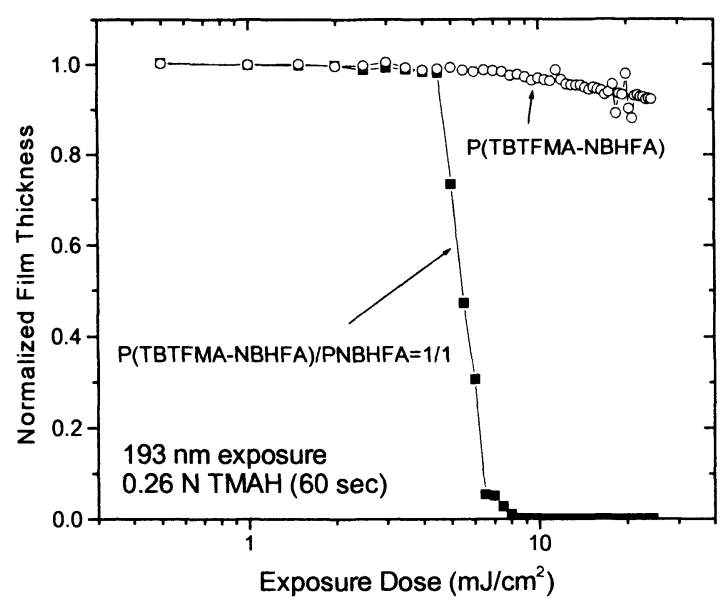

Figure 10 Contrast curves for copolymer and blend resists at $193 \mathrm{~nm}$

Figure 11 presents a scanning electron micrograph of relaxed $120 \mathrm{~nm}$ line/space patterns printed in a P(TBTFMA-NBHFA)-PNBHFA blend resist on an ISI $193 \mathrm{~nm}$ mini-stepper $(0.6$ NA) using a chrome-on-glass mask. The blend resin film had OD of $0.06 / \mu \mathrm{m}$ at $193 \mathrm{~nm}$. Sub100-nm line/space patterns obtained at $157 \mathrm{~nm}$ using an Exitech mini-stepper ( $0.60 \mathrm{NA}$ ) and an alternating phase shift mask are presented in Figure 12. A P(TBTFMA-NBHFA)-PNBHFA blend film with OD of $2.0 / \mu \mathrm{m}$ at $157 \mathrm{~nm}$ was employed in this imaging experiment. Relaxed 80 $\mathrm{nm}$ and dense $90 \mathrm{~nm}$ features were nicely delineated in a 1130 A thick film using a $0.26 \mathrm{~N}$ developer.

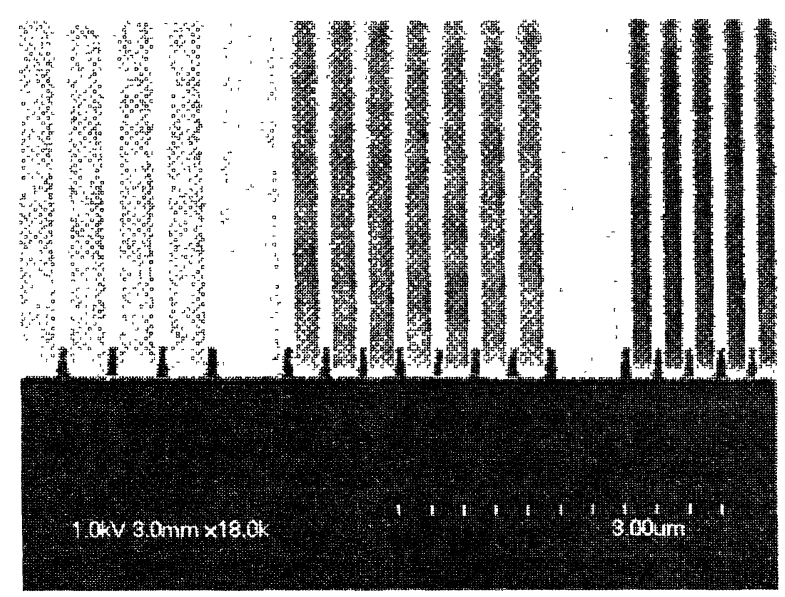

Figure 11 Relaxed $120 \mathrm{~nm}$ line-space patterns printed in a blend resist at $193 \mathrm{~nm}$ (ISI 0.6 NA, COG) 

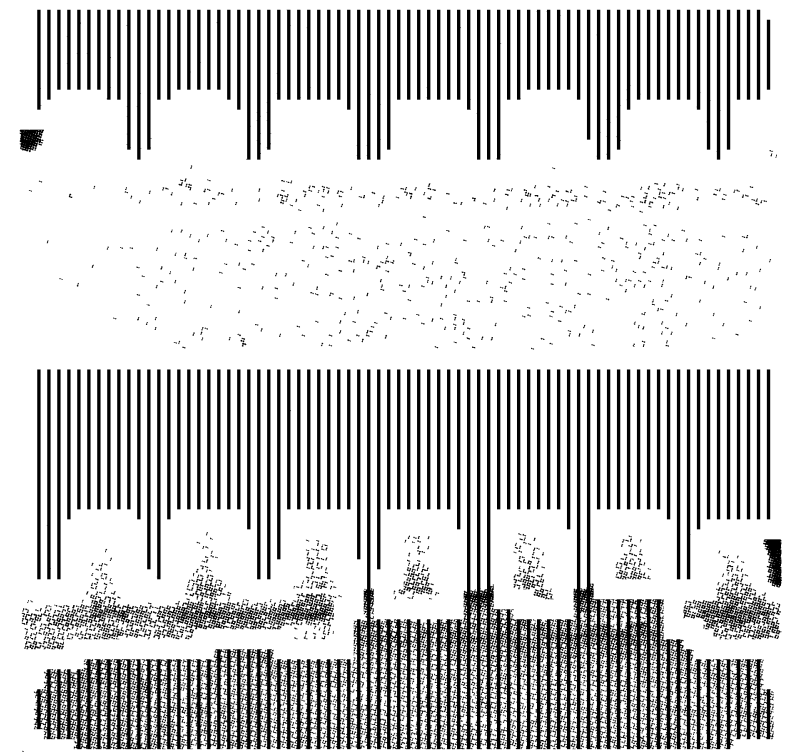

Figure $12157 \mathrm{~nm}$ imaging of blend resist

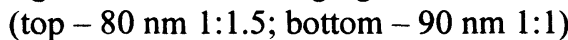

(Exitech 0.6 NA, PSM)

\section{Summary}

Our aliphatic platform for $157 \mathrm{~nm}$ lithography is based on a copolymer of 2trifluoromethylacrylic monomer with NBHFA, which can be prepared by radical polymerization. The mechanism of this novel radical copolymerization has been investigated by determining monomer reactivity ratios and by analyzing copolymerization kinetics in situ by ${ }^{1} \mathrm{H}$ NMR. Copolymerization of TBTFMA and TFMAA with norbornene derivatives (NB and NBHFA) does not follow the terminal model but can be described by the penultimate model. While the copolymerization of TBTFMA with STHFA $\left(\mathrm{PF}^{2}\right.$-ESCAP) can be better interpreted by the penultimate model, the TBMA-STHFA pair (PFESCAP) copolymerizes according to the terminal model. Copolymers of TBTFMA with vinyl ether derivatives, which can be prepared by radical polymerization, have been identified as a novel aliphatic platform. A new approach toward reduction of $157 \mathrm{~nm}$ OD (to $2 / \mu \mathrm{m}$ ) and balancing lipophilicity-hydrophilicity has been proposed. Homogeneous blends of the copolymers with PNBHFA are employed as resist resins, taking advantage of the high transparency $(1.7 / \mu \mathrm{m}$ at 157 $\mathrm{nm}$ and $0.04 / \mu \mathrm{m}$ at $193 \mathrm{~nm}$ ) and hydrophilicity of the NBHFA homopolymer. The above-mentioned copolymers can function as a dissolution inhibitor of PNBHFA. The blend formulations have demonstrated promising lithographic results at 157 and $193 \mathrm{~nm}$. Further optimization work is under way.

\section{Acknowledgments}

PNBHFA employed in this study was supplied by Larry Rhodes (Promerus), which is gratefully acknowledged. The authors thank Mark Sherwood for running his $500 \mathrm{MHz} \mathrm{NMR}$ instrument to quantify residual PGMEA, Leanne Hopper, Rich Siemens, and Heidi Merkins for their GPC and thermal measurements, Jeff Meute and Stefan Hien (SEMATECH) for their assistance in $157 \mathrm{~nm}$ imaging, and Blake Davis for his $193 \mathrm{~nm}$ exposure.

\section{References}

1. R. R. Kunz, T. M. Bloomstein, D. E. Hardy, R. B. Goodman, D. K. Downs, and J. E. Curtin, Proc. SPIE , 3678 (1999) 13.

2. a) H. Ito, G. M. Wallraff, P. Brock, N. Fender, H. Truong, G. Breyta, D. C. Miller, M. H. Sherwood, and R. D. Allen, Proc. SPIE, 4345 (2001) 273; b) H. Ito, G. M. Wallraff, N. Fender, P. J. Brock, C. E. Larson, H. D. Truong, G. Breyta, D. C. Miller, M. H. Sherwood, and R. D. Allen, J. Photopolym. Sci. Technol., 14 (2001) 583; c) H. Ito, G. M. Wallraff, N. Fender, P. J. Brock, W. D. Hinsberg, A. Mahorowala, C. E. Larson, H. D. Truong, G. Breyta, and R. D. Allen, J. Vac. Sci. Technol., B19(6) (2001) 2678; d) H. Ito, G. Wallraff, N. Fender, P. Brock, H. Truong, C. Larson, G. Breyta, and B. Allen, Arch Interface '01CD 2001.

3. a) T. Chiba, R. J. Hung, S. Yamada, B. Trinque, M. Yamachika, C. Brodsky, K. Paterson, A. V. Heyden, A. Jamison, S.-H. Lin, M. Somervelle, J. Byers, W. Conley, and C. G. Willson, J. Photopolym. Sci. Technol., 13 (2000) 657; b) R. J. Hung, H. V. Tran, B. C. Trinque, T. Chiba, S. Yamada, D. P. Sanders, E. F. Connor, R. H. Grubbs, J. Klopp, J. M. J. Frechet, B. H. Thomas, G. J. Shafer, D. D. DesMarteau, W. Conley, and C. G. Willson, Proc. SPIE, 4345 (2001) 385; c) H. V. Tran, R. J. Hung, T. Chiba, S. Yamada, T. Mrozek, Y.-T. Hsieh, C. R. Chambers, B. P. Osborn, B. C. Trinque, M. J. Pinnow, D. P. Sanders, E. C. Connor, R. H. Grubbs, W. Conley, S. A. MacDonald, and C. G. Willson, J. Photopolym. Sci. Technol., 14 (2001) 669.

4. N. Fender, P. J. Brock, W. Chau, S. Bangsaruntip, A. Mahorowala, G. M. Wallraff, 
W. D. Hinsberg, C. E. Larson, H. Ito, G. Breyta, K. Burnham, H. Truong, P. Lawson, and R. D. Allen, Proc. SPIE, 4345 (2001) 417.

5. a) P. R. Kunz, R. F. Sinta, M. Sworin, W. A. Mowers, T. H. Fedynyshyn, V. Liberman, and J. E. Curtin, Proc. SPIE, 4345 (2001) 285; b) T. H. Fedynyshyn, R. R. Kunz, R. F. Sinta, M. Sworin, W. A. Mowers, R. B. Goodman, and S. P. Doran, Proc. SPIE, 4345 (2001) 296.

6. T. Kelen and F. Tüdös, J. Macromol. Sci., Chem. A9 (1975) 1.

7. P. R. Bevington, Data Reduction and Error Analysis for the Physical Sciences, McGrawHill, New York, 1969.

8. H. Ito, C. Dalby, A. Pomeranz, M. Sherwood, R. Sato, R. Sooriyakumaran, K. Guy, and G. Breyta, Macromolecules, 33 (2000) 5080.

9. H. Ito, D. Miller, N. Sveum, and M. Sherwood, J. Polym. Sci., Part A, Polym. Chem., 38 (2000) 3521.

10. H. Ito, D. Fenzel-Alexander, and G. Breyta, Proc. SPIE, 3049 (1997) 575.
11. H. Ito, D. Fenzel-Alexander, and G. Breyta, $J$. Photopolym. Sci. Technol., 10 (1997) 397.

12. H. Ito, R. D. Allen, J. Opitz, T. I. Wallow, H. D. Truong, D. C. Hofer, P. R. Varanasi, G. M. Jordhamo, S. Jayaraman, and R. Vicari, Proc. SPIE, 3999 (2000) 2.

13. H. Ito, B. Giese, and R. Engelbrecht, Macromolecules, 17 (1984) 2204.

14. H. Ito, D. C. Miller, and C. G. Willson, Macromolecules, 15 (1982) 915.

15. S.-J. Choi, H.-W. Kim, S.-G. Woo, J.-T. Moon, Proc. SPIE, 3999 (2000) 54.

16. a) H. Ito and M. Sherwood, Proc. SPIE, 3678, (1999) 104 ; b) H. Ito and M. Sherwood, J. Photopolym. Sci. Technol., 12 (1999) 625.

17. a) H. Ito and E. Flores, J. Electrochem. Soc., 135 (1988) 2322; b) H. Ito, Proc. SPIE, 920 (1988) 33.

18. H. Ito, IBM J. Res. Dev., 45 (2001) 683.

19. W. D. Hinsberg, S. W. Lee, H. Ito, D. E. Horne, and K. K. Kanazawa, Proc. SPIE, 4345 (2001) 1 . 